\title{
GRINBERG, Lúcia. Partido político ou bode expiatório. Um estudo sobre a Aliança Renovadora Nacional (ARENA), 1965-1979. Rio de Janeiro: Mauad X, 2009, 301p. \\ João Leonel da Rosa Pantoja*
}

O estudo de Lúcia Grinberg sobre a ARENA tem o mérito de valorizar duas funções essenciais da pesquisa histórica. Seu livro, primeiro, é uma história que estuda criticamente o passado, que vai às fontes, que, com seus métodos e descobertas, questiona a rigidez e a solidez de memórias sociais específicas. Segundo, toma a memória social como objeto de investigação. Quem as reproduz, as difunde, muitas vezes não possui consciência do processo pelo qual tal construção memorialística passou até chegar a sua forma final. A memória também é histórica. Ela também foi construída ao longo do tempo para legitimar práticas e propostas.

Afinal, pergunta-se Lúcia, qual ARENA ela encontrou ao iniciar suas pesquisas? O primeiro indício é a reação de seus colegas de pós-graduação. Riram. Perguntaram se ela não teria se enganado, se não pretendia pesquisar o Teatro de Arena. Além do seu círculo social, a autora identificou uma memória claramente estabelecida sobre o partido na década de 1990. Entre vários exemplos, cita o caso de membros do PFL que, em 1995, esforçavam-se para desvincular a imagem do partido criado em 1985 com a memória negativa sobre a ARENA. Em resumo, a ARENA seria o partido do adesismo irrestrito aos mandos militares e, também, um partido artificial, sem representatividade alguma, simples instrumento utilizado pelos militares para dar ares de legitimidade aos seus governos. O que Lúcia quer entender é: serão verdades todas as generalizações que atualmente se fazem sobre a ARENA? Como tais generalizações se construíram? A quais propósitos serviram? E qual a importância de criticá-las para uma nova visão sobre o período da ditadura militar?

É a partir do início da ARENA que podemos ver os primeiros problemas. Não foi formada apenas por antigos udenistas que apoiaram o movimento de 64. A diferença entre o número de parlamentares udenistas que foram para a ARENA e ex-membros do PSD é de apenas 08 membros. Ex-udenistas contribuíram com 86 parlamentares e exmembros do PSD com 78. Estava certo o jornalista Villas-Boas-Corrêa ao brincar que a ARENA seria a filha da UDN que caiu na zona? Ou o partido foi inicialmente formado por setores políticos conservadores que não estavam apenas na UDN?

* Mestrando em História Social pela Universidade de Brasília. Contato: jotaleonel@ gmail.com 
Aliás, por políticos com grande experiência eleitoral, com nomes conhecidos pelos eleitores. A autora traz uma lista com o nome de todos os primeiros membros do diretório nacional da ARENA, sua filiação partidária antiga e os cargos públicos que tinham ocupado. Nenhum deles surgiu do nada. Lideranças nacionais como Benedito Valadares, Milton Campos, Gustavo Capanema e Magalhães Pinto tornaram-se arenistas. O que indica, para a autora, certo consenso entre as elites conservadoras brasileiras e, principalmente, que a ARENA tinha uma representação social historicamente associada aos nomes que congregou, representação esta que não pode ser negada. Cairia mais um mito: o da ARENA como um partido biônico, sem valor social, sem representação.

Afinal, Lúcia quer ver a ARENA não apenas como uma criação institucional artificial, mas como um sintoma de algo mais amplo, de características conservadoras da sociedade brasileira. Para reforçar seu argumento, traz cartas enviadas para o Diretório Nacional do partido de cidadãos comuns, não ligados diretamente à política. Cartas de apoio ao partido. De defesa dos abstratos princípios da Revolução de 64, contra o comunismo, contra os baderneiros, contra a anarquia que teria se instalado antes da retirada de Goulart do Poder.

Outro mito que Lúcia derruba é a da relação eternamente dócil entre ARENA e governos militares. Sua análise mais forte é sobre o chamado caso "Márcio Moreira Alves”. Por críticas feitas à invasão da Universidade de Brasília pelos militares, Márcio Moreira Alves tornou-se alvo de ódio por parte dos setores mais radicais das Forças Armadas. A pressão foi tão grande que o Executivo pediu licença ao Congresso para cassar o mandato do Deputado. Chega ao plenário o pedido e, ao contrário do que insinuaria a idéia do "sim, senhor", da subserviência irrestrita, do total de 216 deputados que rejeitaram o pedido, 95 eram da ARENA.

Um dia depois, Costa e Silva baixa o AI-5. E o governo passa a tratar o "seu" partido de forma diferente. Lideranças "liberais" da ARENA se afastaram de posições de comando, como Daniel Krieger, Milton Campos e Carvalho Pinto. Mas Lúcia salienta a obscuridade do período imediatamente após o AI-5. Os arquivos da ARENA pouco dizem. O que lhe restou, diz, foi procurar na imprensa declarações de arenistas. Uma delas é exemplar de como o caso Márcio Moreira Alves é um marco para a história da relação entre ARENA e os militares. Geraldo Freire, líder da ARENA na Câmara dos Deputados, teria declarado a jornalistas que seria necessário a criação de um novo partido. A ARENA teria falhado. Era rebelde. O que o regime precisava era 
efetivamente de um partido do "sim, senhor", da rendição incondicional aos mandos dos militares.

Outra solução seria a manutenção da ARENA, precedida por uma limpeza ideológica. Os elementos possivelmente rebeldes deveriam ser retirados do partido. E foi o que o governo fez. 27 parlamentares efetivos da ARENA foram cassados. Contando os 06 suplentes cassados, o total é de 31. Politicamente, a principal arma utilizada contra a ARENA foi a aprovação da Emenda Constitucional número 1. Ela previa a perda do mandato do parlamentar que por votos ou atitudes contrariasse as diretrizes estabelecidas pelas lideranças partidárias. Seria uma forma de controlar os arenistas sem recorrer a expedientes como o fechamento do Congresso. Como as lideranças eram escolhidas pelos governos militares, tornou-se realmente mais tranqüilo para o Executivo comandar o seu partido de sustentação. Percebe-se, portanto, como a história da relação entre ARENA e governo não foi estática. Teve seu dinamismo.

A autora traz outros episódios evidentemente menores que marcaram certas distâncias entre a ARENA e o governo até o período que considera o de liberalização do regime, 1974-1979. Nele, inicia-se a construção de um dos clichês solidificados na memória social atual sobre a ARENA: o partido do "sim, senhor". Segundo a autora, com a maior liberalização do regime a partir de 1974, e com as vitórias eleitorais do $\mathrm{MDB}$, os embates parlamentares tornaram-se mais ácidos, mais competitivos. E uma das formas dos parlamentares do MDB de ridicularizar a ARENA era acentuar sua subserviência. Ao estudar documentos internos do partido, Lúcia salienta como o "sim, senhor" incomodou os arenistas. Não eram discursos feitos para o público, para serem divulgados, eram discussões privadas que mostravam o grande incômodo que os parlamentares sentiam com as provocações do MDB.

Para continuar a historicização da memória solidificada atualmente sobre a ARENA, Lúcia sai do parlamento e vai para a imprensa. Analisa principalmente charges publicadas em jornais de grande circulação, como o Estado de São Paulo e o Correio da Manhã. A explicação para o estudo e análise das charges é simples: em momentos autoritários, a imprensa é obrigada a recorrer a estratégias alternativas para abrir o mínimo de espaço que seja para a crítica, e o humor é uma das principais.

A autora analisa diversas charges que repetem temas como a indecisão da ARENA, sua falta de identidade, mas as partes mais interessantes são sobre as charges que falam sobre a relação da ARENA com o governo. Nelas, a ARENA é quase sempre representada como uma mulher. Sempre em posição de subordinação, cozinhando para 
o marido "governo", ou se pintando e arrumando para o amante "governo". Charges mais críticas representavam a ARENA como uma prostituta ou uma boneca inflável, dois objetos de desejo que se venderiam fácil para os militares. Uma das charges, por exemplo, mostra uma mulher toda pintada e arrumada, usando uma saia com ARENA escrito e, suspirando, diz: "ele sorriu pra mim...ele sorriu pra mim..." E, ao longe, vemos as costas de um militar. Em outra charge, de Hilde Weber, publicada no ESP em 7/2/1969, a ARENA é representada como uma mulher pobre, usando roupas sujas e esburacadas, com lágrimas nos olhos ao ver que as portas de uma casa estão sendo abertas a ela. O nome da casa: governo. O título da charge: volta ao lar. Há, no entanto, uma importante ressalva feita pela autora: as charges feitas no período militar sobre a ARENA não seriam tão virulentas e ridicularizadoras como as feitas na década de 1990. Isso indicaria uma mudança ainda maior de atitude da sociedade brasileira da década de 1990 sobre o período militar, devedora, diz, do processo de redemocratização iniciado na década de 1980 que, para se legitimar, ridicularizou e repudiou fortemente os militares e a ditadura em geral.

Eis que Lúcia conclui, a partir de seu estudo: a ARENA atuou muitas vezes como partido político realmente, tendo representação social digna de ser considerada como parte importante da cultura política de determinados setores da sociedade brasileira, mas a ARENA também foi um bode expiatório. A partir da transição democrática, a ARENA e os militares foram inteiramente responsabilizados pelos tempos ditatoriais. Os militares seriam os gorilas, a força bruta, ignorante. E a ARENA, a parte fraca, covarde, que não só não resistiu como apoiou a ditadura e todos os seus feitos.

E aí está o maior mérito da pesquisa feita por Lúcia Grinberg. Ridicularizar a ARENA e os militares, diz, é ignorar que setores importantes e representativos da sociedade brasileira também apoiaram o regime militar. Lúcia se recusa a pensar a ARENA como uma entidade vazia. Não, suas atitudes, sua construção, os votos que recebeu mesmo quando havia a possibilidade do MDB, apesar de todas as restrições eleitorais, indicam, sim, representatividade. Indicam, sim, que a ditadura militar brasileira não se sustentou por tanto tempo apenas pela habilidade dos militares e dos políticos que teriam apoiado o regime. Indicam, finalmente, que é importante tirar a ditadura militar e a ARENA do campo da memória para melhor entendermos o período de 64-79. É a graça das piadas sobre a ARENA que nos impede de olhar além, criticamente. É verdade, por fim, que a autora desconstrói piadas e nos tira algumas 
boas risadas, mas nos propõe algo valioso em troca: um olhar crítico que traga de volta como objeto de pesquisa o grande elemento silencioso do período militar, a sociedade civil.

\section{Referências Bibliográficas}

GRINBERG, Lúcia. Partido político ou bode expiatório: Um estudo sobre a Aliança Renovadora Nacional (ARENA), 1965-1979. Rio de Janeiro: Mauad X, 2009. 